\title{
Radical-Scavenging Activity of a Sunscreen Enriched by Antioxidants Providing Protection in the Whole Solar Spectral Range
}

\author{
Carla Souza $^{a}$ Patrícia Maia Campos $^{a}$ Sabine Schanzer ${ }^{b}$ Stephanie Albrecht ${ }^{b}$ \\ Silke B. Lohan ${ }^{b}$ Jürgen Lademann ${ }^{b}$ Maxim E. Darvin ${ }^{b}$ Martina C. Meinke ${ }^{b}$ \\ a Laboratory of Cosmetic Technology, Faculty of Pharmaceutical Sciences of Ribeirão Preto, University of \\ São Paulo, Ribeirão Preto, Brazil; ${ }^{b}$ Center of Experimental and Applied Cutaneous Physiology (CCP), Department of \\ Dermatology, Charité - Universitätsmedizin Berlin, Berlin, Germany
}

\section{Keywords}

Radical formation - Electron paramagnetic resonance spectroscopy · Confocal Raman microscopy · Skin penetration profile $\cdot$ Sunscreen $\cdot$ Antioxidants

\begin{abstract}
Background/Aim: The main reason for extrinsic skin aging is the negative action of free radicals. The formation of free radicals in the skin has been associated with ultraviolet (UV) exposure and also to visible (VIS) and near-infrared (NIR) irradiations. The aim of the present study was to evaluate the efficacy of a sunscreen in the whole solar range. Methods: The radical-scavenging activity of a sunscreen in the UV, VIS, and NIR ranges was evaluated using electron paramagnetic resonance spectroscopy. Ex vivo penetration profiles were determined using confocal Raman microscopy on porcine ear skin at different time points after application. Results: Compared to the untreated skin, the sunscreen decreased the skin radical formation in the UV and VIS regions. Additional protection in the VIS and NIR ranges was observed for the sunscreen containing antioxidants (AO). The penetration depth of the cream was less than $11.2 \pm 3.0 \mu \mathrm{m}$ for all time
\end{abstract}

\section{KARGER}

(c) 2017 S. Karger AG, Basel

E-Mail karger@karger.com

www.karger.com/spp points. Conclusion: A sunscreen containing AO improved the photoprotection in the VIS and NIR ranges. The sunscreen was retained in the stratum corneum. Therefore, these results show the possibility of the development of effective and safer sunscreen products.

(c) 2017 S. Karger AG, Basel

\section{Introduction}

The effects caused by exposure to ultraviolet (UV; 280 $400 \mathrm{~nm}$ ) radiation are well documented in the literature [1, 2]; however, the effects of visible (VIS; 400-760 nm) and near-infrared (NIR; 760-3,000 $\mathrm{nm}$ ) radiations have not yet been fully elucidated, and recent studies have evaluated their effects on the skin [3-5]. It is well known that moderate sun exposure is essential for the vitamin $\mathrm{D}$ synthesis that is fundamental for the bone and muscle status [6]. The therapeutic action of NIR radiation has also been reported [4], but excessive exposure to solar radiation has potential negative effects for human health and should therefore be handled with adequate photoprotection, which is most efficiently achieved with the proper use of sunscreens. 
It is generally accepted that UV radiation is causally related to sunburns, photoaging, and skin cancer after long-term exposure [3]. UVA radiation reaches deeper skin layers than UVB and is mainly responsible for the generation of reactive oxygen species (ROS) and reactive nitrogen species (RNS), which damages the DNA and proteins, contributing to photoaging $[1,2]$. Up to $95 \%$ of the visible signs of skin aging are a consequence of exposure to sunlight [7]. On the other hand, UVB is known to directly damage DNA, promoting mutations that are responsible for basal and squamous cell carcinoma $[2,4]$. Similarly to UVA radiation, visible light and infrared A radiations penetrate deep into the dermis and also generate ROS, causing oxidative stress to skin, resulting in skin aging, carcinogenesis, and, additionally, affecting the mitochondrial integrity $[8,9]$. There is increasing evidence that visible light can damage human skin [10-12].

Taking this knowledge into account, it is suggested that photoprotection of human skin should not be limited to UV; also VIS and infrared A radiation should be included $[8,13,14]$. Additionally, considering the efficacy and safety of these products, the skin penetration of UV absorbers must also be considered, once they have to stay in the skin surface in order to guarantee the sunscreen's efficacy and safety $[15,16]$. Therefore, the aim of this study was to evaluate the in vitro efficacy and safety of a sunscreen containing antioxidants $(\mathrm{AO})$ in the whole solar spectral range by evaluating the radical formation on porcine ear skin after UV, VIS, and NIR radiation and the skin penetration profile.

In addition to UVA and UVB filters, the proposed sunscreen contains a combination of the AO Spirulina and dimethylmethoxy chromanol (DMC). The specific UV absorbers selected for study were diethylamino hydroxybenzoyl hexyl benzoate (DHHB), bis-ethylhexyloxyphenol methoxyphenyl triazine (BEMT), methylene bis-benzotriazolyl tetramethylbutylphenol (MBBT), and ethylhexyl triazone (EHT). These 4 molecules were evaluated because they are present in most commercial products in the market, and when formulated in combination provide protection from UVB and UVA radiation. Spirulina is a green microalga obtained by a biotechnological process that presents a rich composition of provitamin A, vitamin $\mathrm{B}$, proteins, and polysaccharides, with great $\mathrm{AO}$ activity and that may also assist in maintaining skin eudermia [17-19]. DMC is a synthetic analog of $\gamma$-tocopherol, capable of neutralizing both ROS and RNS, which is a great advantage compared to the other known $\mathrm{AO}$ that are capable to react with only 1 of those species.
Table 1. Active ingredient composition of sunscreens

\begin{tabular}{|c|c|c|}
\hline \multirow[t]{2}{*}{ Composition } & \multicolumn{2}{|c|}{$\begin{array}{l}\text { Concentration, } \\
\% \mathrm{w} / \mathrm{w}\end{array}$} \\
\hline & $\begin{array}{l}\text { cream } \\
1\end{array}$ & $\begin{array}{l}\text { cream } \\
2\end{array}$ \\
\hline Bis-ethylhexyl metoxyphenyl triazine $\mathrm{a}^{\mathrm{a}}$ & 4.0 & 4.0 \\
\hline Diethylamino hydroxybenzoyl hexyl benzoate ${ }^{a}$ & 1.0 & 1.0 \\
\hline Ethylhexyl triazone $^{\mathrm{a}}$ & 4.0 & 4.0 \\
\hline Methylene bis-benzotriazolyl tetramethylbutylphenol ${ }^{\mathrm{a}}$ & 6.0 & 6.0 \\
\hline Spirulina dry extract & - & 0.1 \\
\hline DMC-loaded SLN & - & $10.0^{\mathrm{b}}$ \\
\hline
\end{tabular}

DMC-loaded SLN, dimethylmethoxy chromanol-loaded solid lipid nanoparticles. ${ }^{\text {a }}$ Qualitative composition reported in accordance with the International Nomenclature of Cosmetic Ingredients. ${ }^{b}$ The final concentration of DMC into the cream was $0.05 \%$ $(\mathrm{w} / \mathrm{w})$.

Thus, the results presented and discussed in this work may help in understanding the photoprotective effects of UVA/UVB absorbers and AO upon the level of sun-induced ROS generated under UV, VIS, and NIR exposure, as well as in the penetration profile of the UV absorbers, which could be relevant for improving the photoprotection, safety, and efficacy of sunscreen formulations.

\section{Materials and Methods}

Polaxamer 407 and Tween 80 (polysorbate 80) were purchased from Via Farma Ltda (São Paulo, Brazil). Purified beeswax with an esterification index of $70 \%$ and melting point of $54^{\circ} \mathrm{C}$ (batch No. 153475) was supplied by Labsynth Ltda (São Paulo, Brazil). The UV filters BEMT (Tinosorb $\mathrm{S}^{\circledR}$ ), MBBT (Tinosorb $\mathrm{M}^{\circledR}, 50 \%$ MBBT in a dispersion of propylene glycol, decyl glucoside and xanthan gum), DHHB (Uvinul APlus ${ }^{\circledR}$ ), and EHT (Uvinul T150 ${ }^{\circledR}$ ) were provided by BASF Personal Care and Nutrition (Monheim, Germany), DMC (Lipochroman ${ }^{\circledR}$ ) by Lipotec SAU (Barcelona, Spain), and Spirulina dry extract by Ouro Fino Agronegócios (Ribeirão Preto, Brazil). Nitroxide PCA (3-carboxy-2,2,5,5-tetramethyl-1-pyrrolidinyloxy) and DPPH (1,1-diphenyl-2-picrylhydrazyl) were purchased from Sigma-Aldrich (Steinheim, Germany). All other chemicals used were of analytical grade.

\section{Composition of the Sunscreen Formulation}

The investigations were carried out for the different sunscreen formulations described in Table 1, formulated by an oil-in-water emulsification technique [20]. DMC-loaded solid lipid nanoparticles (SLN) were incorporated in cream 2 at $10 \%(\mathrm{v} / \mathrm{w})$, and the final concentration of DMC in this cream was $0.05 \%(w / w)$. Both studied formulations had SPF 30 and good UVA protection. After preparation they were stored at $25.0 \pm 2.0^{\circ} \mathrm{C}$ hermetically closed.
Souza et al. 


\section{Formulation of DMC-Loaded SLN}

Due to the DMC instability after incorporation into cosmetic formulations, DMC was incorporated into SLN. DMC-loaded SLN were prepared by the hot melt microemulsion technique using beeswax as solid lipid at 5.0\% (w/v) and DMC at 0.5\% (w/v). The authors have already described the main results of the characterization of this system. The nanoparticles were spherical in shape with an average size, polydispersive index and zeta potential equal to $120.6 \pm 24.2 \mathrm{~nm}, 0.384 \pm 0.027$ and $-10.5 \pm 0.88 \mathrm{mV}$. After 54 days of storage at $4.0 \pm 2.0^{\circ} \mathrm{C}$, these values were $133.69 \pm 23.03 \mathrm{~nm}$, $0.411 \pm 0.032$ and $-10.8 \pm 0.65 \mathrm{mV}$. The efficient DMC SLN entrapment was $96.0 \pm 0.81$ and $95.0 \pm 3.72 \%$ after $24 \mathrm{~h}$ and 30 days, respectively (unpubl. results).

\section{Electron Paramagnetic Resonance Spectroscopy}

Electron paramagnetic resonance (EPR) spectroscopy is based on resonant microwave absorption of a sample with unpaired electrons in an external magnetic field [21]. In this study EPR (X-band EPR spectrometer MiniScope MS400, Magnettech, Berlin, Germany) was used in order to determine the radical protection factor (RPF) of the studied formulations as well as to evaluate the radical formation on porcine skin, as described below.

For the RPF determination, the following parameter settings were used: modulation amplitude $2 \mathrm{GHz}$, microwave (MW) attenuation $15 \mathrm{~dB}(\mathrm{MW}$ power $3.16 \mathrm{~mW})$, gain 1 , sweep time $20 \mathrm{~s}$, sweep $95.25 \mathrm{GHz}, \mathrm{B}_{0}$ field 3,371.53 GHz, step 4,096, and number (pass) 1. For the determination of skin radical formation, the following parameter settings were used: modulation $2 \mathrm{GHz}, \mathrm{MW}$ attenuation $10 \mathrm{~dB}(\mathrm{MW}$ power $10 \mathrm{~mW})$, gain 100, sweep time $20 \mathrm{~s}$, sweep $53.34 \mathrm{GHz}, \mathrm{B}_{0}$ field 3,358.36 GHz, step 4,096, and number (pass) 1.

Determination of the RPF of the Sunscreens

For the determination of the RPF, DPPH (Sigma-Aldrich, Steinheim, Germany) was used as a test radical. DPPH is detectable by EPR spectroscopy emitting a characteristic signal, which is directly dependent on the DPPH concentration of the sample. When the AO system of the tested formulation reacts with DPPH, the signal intensity is reduced over time. The number of reduced test radicals represents the radical-scavenging activity of the cream that is normalized to $1 \mathrm{mg}$ input of the product. The RPF is calculated by the following equation:

$$
\mathrm{RPF}=\frac{\mathrm{RC} \times \mathrm{RF}}{\mathrm{PI}}
$$

whereby RC is the concentration of the test radical (radicals per milliliter), RF is the reduction factor, which represents the difference between the untreated test radical intensity and the decreased signal intensity after treatment with the AO normalized to the signal of the untreated test radical, and PI is the product input, which represents the amount of the substance/product measured in milligrams per milliliter; the RPF is expressed as $10^{14}$ radicals/mg $[22,23]$

For the measurements, the samples were prepared as follows: $40 \mathrm{mg}$ of each formulation was solubilized in $1.2 \mathrm{~mL}$ ethanol, followed by a dilution (1:1) with a $1 \mathrm{mM} \mathrm{DPPH}$ ethanolic solution. The samples were kept under constant agitation, and measurements were carried out after $0,1,2,3,4,5$, and $6 \mathrm{~h}$, until stabilization of the DPPH signal.

Radical-Scavenging Activity of a

Sunscreen
Radical Formation on Porcine Skin

Skin Samples. Ex vivo evaluation of the skin radical formation was carried out on porcine ear skin samples, which is a highly suitable model for human skin $[24,25]$. Porcine ears were delivered freshly from a local butcher and were used until 2 days later. Before the experiments, the skin was cleaned with cold water, dried with paper towels, dermatomed at a thickness of $300 \mu \mathrm{m}$ and kept at $4{ }^{\circ} \mathrm{C}$ until the time of the experiments.

Spin Probe. The spin probe nitroxide PCA (Sigma-Aldrich, Steinheim, Germany) was used that possesses a free, unpaired electron in the outer shell of the molecule and is therefore detectable by EPR spectroscopy. PCA hardly reacts with skin AO but well with induced short-lived free radicals, which recombine with PCA turning the spin probe EPR-silent. Therefore, PCA reduction is correlated with free radical production [26].

Irradiation Source. For in situ irradiation of the samples, a sun simulator (Sun Simulator LOT Oriel GmbH \& Co. KG, Germany, classified to IEC 60904-9, class A) was used with a VIS/NIR or UV/ VIS fiber-coupled sun simulator (LOT Oriel GmbH \& Co. KG). In addition to the sun simulator filter AMO filter LSZ185 (air mass 0, outer space), the following transmission filters were added in order to limit the different spectral ranges: 400FH90-50S filter ( $>400$ $\mathrm{nm})$, PGO-57400 filter $(400-700 \mathrm{~nm})$ and 001FG09-50S filter (transmission $331-383 \mathrm{~nm}, 10 \%$ transmission $730-770 \mathrm{~nm}$ ). The following irradiation intensity was applied for each evaluated spectral range: UVA/UVB radiation (at $500 \pm 30$ and $2.0 \pm 0.1 \mathrm{~mJ} / \mathrm{cm}^{2}$, respectively), VIS radiation (at 10,600 $\pm 60 \mathrm{~mJ} / \mathrm{cm}^{2}$ ) and VIS/NIR radiation (at 19,064 $\pm 60 \mathrm{~mJ} / \mathrm{cm}^{2}$ ), measured, respectively, by the UVA and UVB sensor ILT 1400 Radiometer Photometer (Polytec, Waldbronn, Germany) and the Economic Handheld Optical Power Meter 843-R (Newport Corporation, CA, USA).

Measuring the Radical Formation on Porcine Skin. $2 \mathrm{mg} / \mathrm{cm}^{2}$ of each tested sunscreen, containing or not the AO system, was applied onto the porcine skin surface, according to the COLIPA standard procedure. The cream was allowed to penetrate for $1 \mathrm{~h}$. After that, in order to apply the EPR label, the skin samples were embedded in $150 \mu \mathrm{L}$ of a PBS solution of $100 \mu \mathrm{M}$ PCA and left in contact for $5 \mathrm{~min}$. The remaining PCA solution and cream sample on the skin surface were removed at once with paper towels. Then, the samples were irradiated for $6 \mathrm{~min}$ at UVA/UVB, VIS and VIS/NIR ranges separately and the measurement of the PCA signal by EPR spectroscopy was performed simultaneously every minute. All measurements were performed in duplicate on adjacent skin areas, and repeated on 5 different porcine ear samples. As control, a cream-treated but nonirradiated skin was also measured, as well as untreated and nonirradiated skin samples. The data were normalized to the first measurement and set to time zero, and the skin radical formation before and after protection with each sunscreen sample was calculated by subtracting the data of irradiated samples from those of nonirradiated ones. The radical formation in the NIR region was calculated subtracting the data obtained in the VIS by the data in the VIS/NIR region.

\section{Confocal Raman Microscopy}

Confocal Raman microscopy (CRM) measurements were performed in order to obtain the penetration depth of cream 2, containing UV filters and AO, on porcine ear skin [27, 28]. The pig ears were also delivered freshly from a local butcher. They were used until 2 days later and kept cleaned at $4^{\circ} \mathrm{C}$ until the time of the experiments. 


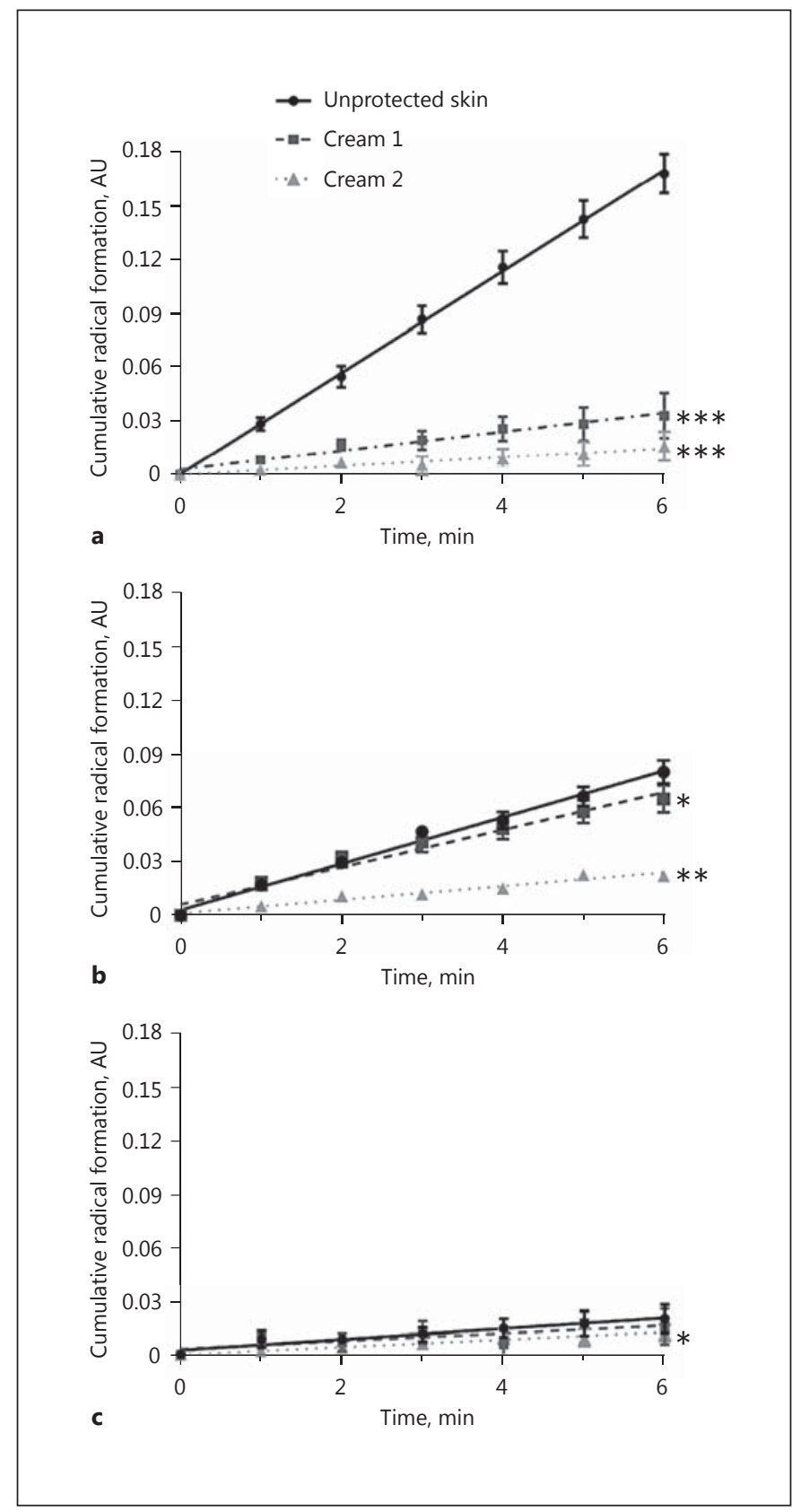

Fig. 1. Cumulative skin radical formation (mean values \pm standard deviation) over time for unprotected and protected porcine ear skin after UVA and UVB (a), VIS (b), and NIR (c) radiation, measured by EPR spectroscopy $(n=10) .{ }^{*} p \leq 0.1,{ }^{* *} p \leq 0.01,{ }^{* * *} p \leq$ 0.001: statistically significant difference in relation to unprotected skin. AO, antioxidant system.

A model 3510 Skin Composition Analyzer (River Diagnostics, Rotterdam, The Netherlands) was used, which is commonly applied for in vivo/ex vivo skin investigations. A NIR laser (785 nm, $20 \mathrm{~mW}$ on the skin surface, exposure time $5 \mathrm{~s}$ ) was used to analyze the porcine ear skin samples in the fingerprint region (400-2,000/

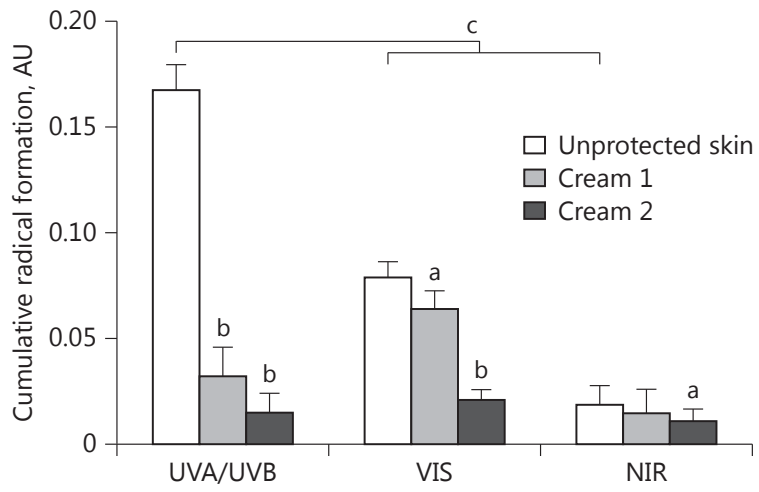

Fig. 2. Cumulative skin radical formation (mean values \pm standard deviation) after 6 min of irradiation in different spectral regions of the sun, before and after cream application on porcine ear skin, measured by EPR spectroscopy $(n=10) .{ }^{\mathrm{a}} p \leq 0.1,{ }^{\mathrm{b}} p \leq 0.001$ : statistically significant difference in relation to unprotected skin; ${ }^{\mathrm{c}} p \leq 0.01$ : statistically significant difference between UV, VIS, and NIR. UVA/B, ultraviolet A and B radiation; VIS, visible radiation; $\mathrm{NIR}$, near-infrared radiation; $\mathrm{AO}$, antioxidant system.

$\mathrm{cm})$. The utilized CRM was described elsewhere [25] and used for the determination of the penetration depth of topically applied substances into the skin $[29,30]$.

The Raman fingerprint spectra were recorded above the skin surface down to a depth of $40 \mu \mathrm{m}$ at increments of $2 \mu \mathrm{m}$. In this case, the detailed Raman spectra were obtained within the epidermis. Skin areas without furrows and hairs were chosen to exclude their influence on the penetration measurements. Three untreated and 5 cream-treated porcine ear samples were measured. For the cream-treated sample, cream 2 was applied on a previously marked area of the skin at an amount of $2.0 \mathrm{mg} / \mathrm{cm}^{2}$, according to the COLIPA standard procedure. After $15 \mathrm{~min}, 1$ and $6 \mathrm{~h}$ of penetration at normal conditions (room temperature $21^{\circ} \mathrm{C}$, relative humidity $35 \%$ on average), the excess of the cream was removed from the skin surface, and CRM measurements were taken at 5 different points at the excised skin sample.

To determine the mean penetration depth value of the cream at each measuring point, the cream-treated and untreated skin spectra were compared by the nonrestricted multiple least square fit method using Skin Tools 2.0 software [25] developed by River Diagnostics. With this method it was possible to calculate the depth-dependent coefficients of each individual skin compound (such as cholesterol, ceramide, keratin, urea, water, etc.) fitting the skin Raman spectra by their known model spectra, minimizing the residual fitting error. These depth-dependent coefficients give information on the semiquantitative concentration of each individual compound. For the cream-treated skin, an additional coefficient of the cream is also determined and serves as the sunscreen relative concentration in the skin. The nonrestricted multiple least square fit method has previously been described in detail elsewhere [30] and used for the determination of penetration profiles of topically applied substances into the skin [25]. 


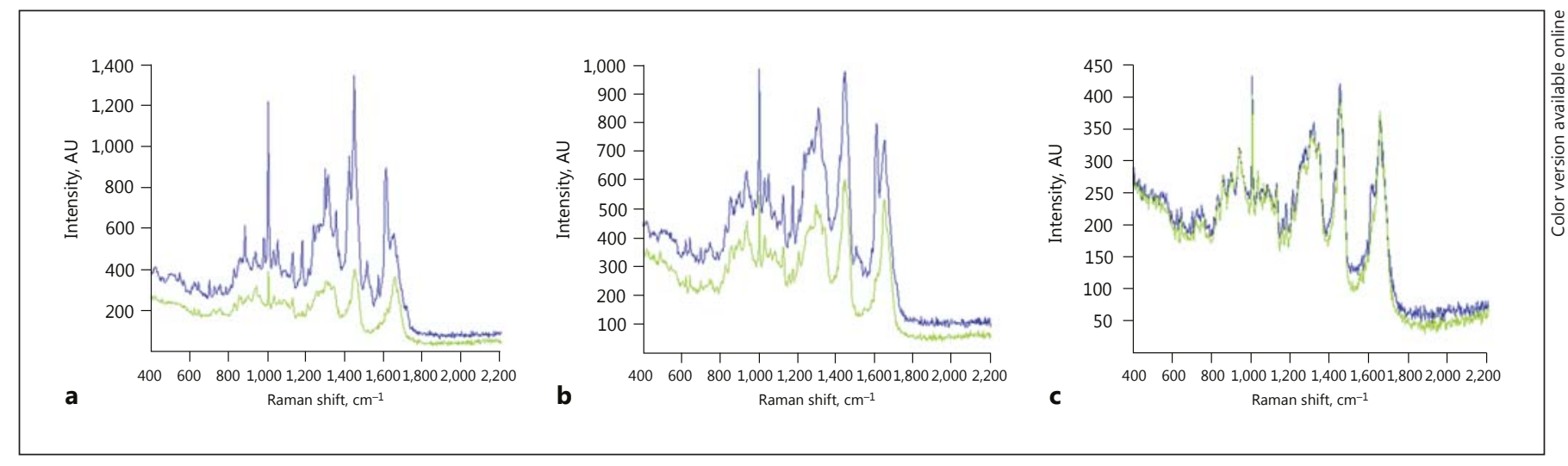

Fig. 3. Raman spectra of porcine ear skin obtained by CRM for cream-treated (blue/black line) and untreated skin (green/gray line) after $15 \mathrm{~h}$ of penetration at a depth of $2 \mu \mathrm{m}(\mathbf{a}), 6 \mu \mathrm{m}(\mathbf{b})$, and $8 \mu \mathrm{m}(\mathbf{c})$.

\section{Statistical Analysis}

All EPR results were analyzed using SPSS for Windows (SPSS Inc., Chicago, IL, USA). The data evaluation for the cumulative radical formation after 6 min of irradiation in different spectral regions of the sun, before and after cream application, was based on the Wilcoxon test for dependent samples, with $p \leq 0.05$ being considered as significant. To evaluate the significance over the entire measurement period, generalized estimating equation was done; a $p \leq 0.05$ was considered as significant.

\section{Results}

\section{Determination of the $R P F$}

The RPFs for cream 1 and cream 2, determined by EPR spectroscopy, were $32 \pm 1$ and $77 \pm 4 \times 10^{4}$ radicals $/ \mathrm{mg}$, respectively, which means that cream 1 had a low radicalscavenging activity and cream 2 presented a good result.

\section{Radical Formation on Porcine Skin}

Figures 1 and 2 show the results of skin radical formation for protected and unprotected porcine ear skin after irradiation in different spectral regions. As can be seen, a significantly higher radical formation was observed after UV, followed by VIS radiation. In the NIR range, the radical formation was low. After sunscreen application, the radical formation in the UV range was the most significantly reduced for either formulation, whether or not containing AO. However, cream 2 (containing AO) was able to significantly decrease the radical formation in the whole spectral range compared to unprotected skin, while cream 1 statistically reduced the radical formation only in the UV and VIS ranges. Comparing the protection between sunscreen formulations, it is clearly demonstrated that the photoprotective effect of the sunscreen containing AO was significantly improved in the VIS region, compared with the sunscreen without $\mathrm{AO}$, with an additional, but quite small protection in the NIR range.

\section{Penetration of Sunscreen}

Finally, the maximum penetration depth of cream 2 was determined. The maximum penetration depth is defined as the minimum peak intensity that the methods can differentiate when the treated and untreated porcine skin spectra are compared in the same depth and spectral range. Figure 3 shows the group of Raman spectra in the range between 400 and $2,200 / \mathrm{cm}^{-1}$ of the untreated and cream-treated porcine skin for 3 exemplary depths after 15 min of skin penetration. The intensity of the cream peak is reduced by increasing the depth into the skin. The difference between untreated and cream-treated skin spectra is visually distinguishable at the depths of $2 \mu \mathrm{m}$ (Fig. 3a) and $6 \mu \mathrm{m}$ (Fig. 3b). At the depth of $10 \mu \mathrm{m}$ (Fig. 3c), the spectra are comparable making it impossible to detect cream in the skin, suggesting absence of penetration at this depth.

The penetration depth of the cream in porcine ear skin after $15 \mathrm{~min}, 1$ and $6 \mathrm{~h}$ is shown in Figure 4 . As can be seen, the maximum of the cream concentration is observed near the skin surface, decreasing until disappearing completely at a depth of $9.0 \pm 1.0,10.4 \pm 1.7$, and 11.2 $\pm 3.0 \mu \mathrm{m}$ after $15 \mathrm{~min}, 1$ and $6 \mathrm{~h}$ of penetration, respectively, which means that even the studied UV filters stayed in the skin surface. No significant differences in the penetration profiles of the cream after $15 \mathrm{~min}, 1$ and $6 \mathrm{~h}$ could be observed. 


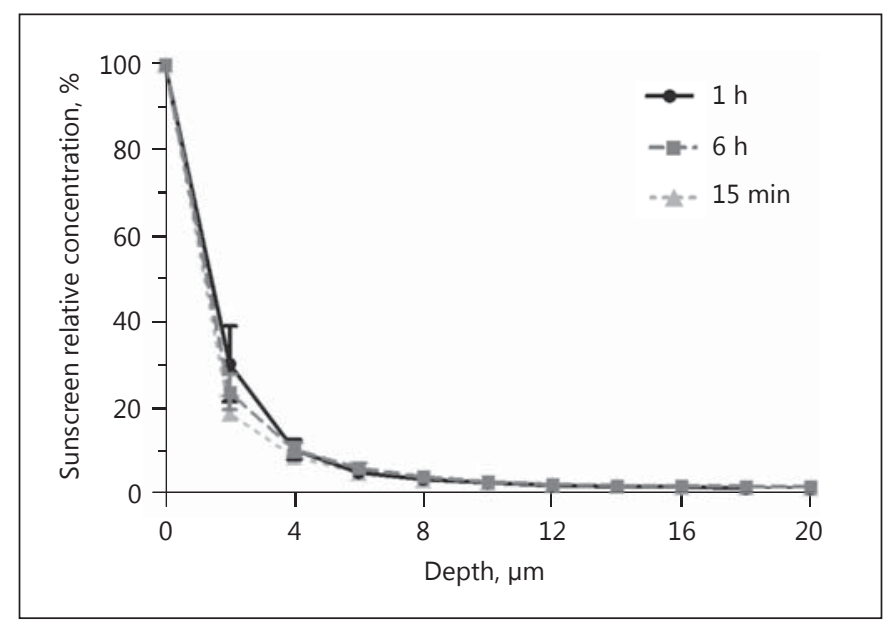

Fig. 4. Penetration profile of the cream's ingredients applied onto intact porcine skin for $15 \mathrm{~min}, 1$ and $6 \mathrm{~h}$ measured by CRM ( $n=$ 5 , mean values \pm standard deviation).

\section{Discussion}

For many years, the focus of photobiology research and photoprotective strategies has centered on the UV portion of the solar spectrum of radiation, in spite of only $5 \%$ of solar radiation reaching the surface of the earth within the UV range, whereas about $40-45 \%$ is visible light, and $50 \%$ is in the longer-wavelength infrared portion $[1,14]$. Several studies reported skin damage due to VIS and NIR radiation $[9,11,13]$, which is mainly related to the generation of free radicals in the skin. Consequently, AO have been added to sunscreen products as a new strategy for protection against the radical formation due to sun exposure $[16,22,31,32]$. Thus, in this study the radical-scavenging activity of a sunscreen containing UVA/UVB filters associated with $\mathrm{AO}$ in the whole solar spectral range was investigated, as well as the skin penetration depth of the developed sunscreen.

The RPFs of the sunscreen formulation, containing or not $\mathrm{AO}$, were evaluated. Cream 1 had the lowest RPF. Since no extra AO were added to this cream, this result can be explained due to the ingredients added on it to prevent the oxidation of the formulation (realizing its stabilization), i.e. butylhydroxy toluene. Cream 2, in turn, showed higher RPF values due to the incorporation of Spirulina $(0.1 \% \mathrm{w} / \mathrm{w})$ and DMC-loaded SLN (DMC at $0.05 \% \mathrm{w} / \mathrm{w}$ ) into the cream. Previous results published by Meinke et al. [23] who estimated the RPF for different commercial brands of sunscreens, obtained values ranging from 40 to $119 \times 10^{14}$ radicals/mg. The COLIPA standard had values around $20 \times 10^{14}$ radicals $/ \mathrm{mg}$, which means low radical-scavenging activity. Therefore, it is possible to attest that the sunscreen containing $\mathrm{AO}$ (cream 2) has an intermediate value with good radical-scavenging activity compared to commercial sunscreens, and it is a good alternative to protect the skin against the sun-induced ROS generation.

Despite the good RPF value of the sunscreen containing $\mathrm{AO}$, it is important to evaluate whether such an activity has a benefit after topical application onto the skin against sun-induced free radical formation. In the present study, higher radical formation was observed in the UV range, followed by VIS and NIR ranges. It has been demonstrated that the radical formation on the skin after exposure to sun radiation is distributed as follows: $64 \%$ in the UV ( $17 \%$ in the UVB and $47 \%$ in the UVA), $36 \%$ in the VIS and NIR regions [13]. Thus, our results agree with previous reports in the literature [13, 22]. Additionally, the radical formation in the NIR range was assessed separately in this study, and a low radical formation was shown compared to UV and VIS ranges.

It was also observed that the radical formation was significantly reduced by sunscreen application for both evaluated formulations, whether or not containing $\mathrm{AO}$, but it cannot be totally avoided. For both creams, the highest protection was observed in the UV range, and we did not see any significant difference between them. This result can be explained based on the characteristics of the organic UV filters used in the formulations (Fig. 5) that mainly provide protection in the UV region, preventing UV-induced ROS generation in the skin. Several studies have demonstrated that sunscreens incorporating UV absorbers are effective in reducing the risk of skin cancer and, consequently, photoaging $[7,33]$.

Additionally the MBBT filter, formulated as Tinosorb $\mathrm{M}^{\circledR}$, also contains $\mathrm{TiO}_{2}$, an inorganic UV filter that is able to scatter the UV and VIS light, which could explain the slight VIS protection observed for cream 1. However, a significantly higher protection was observed in the VIS range for cream 2, containing AO. This result can be explained due to the radical-scavenging activity of the AO (0.1\% w/w Spirulina and 10\% w/w DMC-loaded SLN) added to this cream, neutralizing the free radicals formed by the VIS light on the skin after irradiation and increasing the protection in this spectral range. A synergetic effect between inorganic filters and AO has already been demonstrated in the VIS range [22], in agreement with the results of the present study. In addition, it is important to notice that the scattering properties of Spirulina have already been reported in the VIS range [34], which makes them behave as inorganic filters increasing the
Souza et al. 


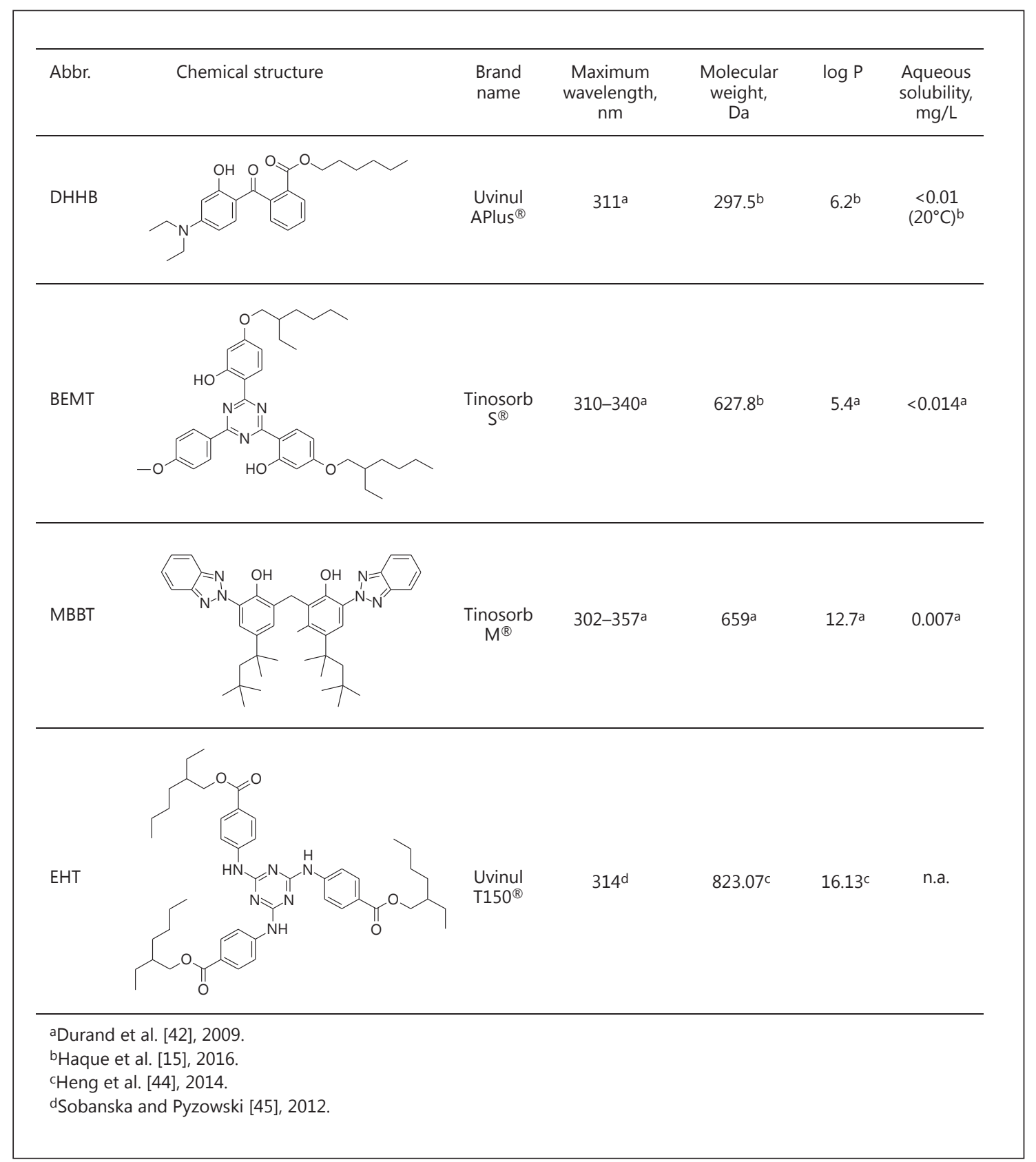

Fig. 5. Physicochemical parameters of DHHB, BEMT, MBBT, and EHT. n.a., not assessed.

protection in that range. Liebel et al. [11] also showed that sunscreens with $\mathrm{AO}$ were effective in preventing VIS-induced ROS.

On the other hand, the radical formation in the NIR range was much lower compared to UV and VIS regions. No protection was observed with cream 1 , and a slight significant protection was observed with cream 2 (Fig. 2), which can also be suggested as the radical-scavenging ac- tivity of the AO present in this cream. A similar result was reported by Meinke et al. [22], who suggested AO to protect against the infrared $\mathrm{A}$ range, but the protection against the radical formation was also too small. Several studies have discussed the effect of NIR radiation, especially infrared A, on the human skin $[3,9,35,36]$. In this study, the NIR irradiance dose was $2.1 \mathrm{~J} / \mathrm{cm}^{2}$ and therefore lower than the natural sunlight radiation, which 
makes a realistic extrapolation to in vivo conditions possible. New results on the comparison between ex vivo and in vivo findings have shown that in vivo many more radicals are formed compared to ex vivo [37]. Therefore, in vivo a protection could be relevant.

CRM measurements were employed to evaluate the skin penetration depth of the sunscreens into the porcine ear skin based on their chemical composition, which means that a Raman spectrum is highly molecule specific $[29,38,39]$. According to our data (Fig. 4), the maximum sunscreen concentration was detectable near the skin surface, at a depth of $11.2 \pm 3.0 \mu \mathrm{m}$ after $6 \mathrm{~h}$ of penetration, respectively. The obtained results are in strong agreement with the lipid-ordering profile of the stratum corneum, which provides the maximum skin barrier function at depths around $10 \mu \mathrm{m}$ [40]. Thus, the majority of the formulation ingredients remains on the skin surface and in the superficial layers, and does not penetrate into the viable layers of the epidermis. The findings of this study are in agreement with the legislation regarding sunscreens, which have demonstrated that UV filters are supposed to stay in the upper skin layers to protect the skin against the harmful effects of solar radiation $[16,41]$.

It is important to note that, as can be seen in Figure 5, all UV filters used in this study are lipophilic molecules with high molecular weights exceeding $600 \mathrm{~g} / \mathrm{mol}$, excepting DHHB filter $(297 \mathrm{~g} / \mathrm{mol})$, and an oil-in-water emulsion with low lipid content was used, decreasing the risk of these molecules to permeate the stratum corneum barrier and reach the epidermis and dermis [42]. In the present study, we did not evaluate the skin penetration depth for each UV filter separately, but according to our CRM measurements, we can confirm that the majority of the UV filter concentrations remained on the skin surface. Other reports in the literature demonstrated similar results for the same UV filters, reinforcing the result of this study $[15,42,43]$.
Finally, considering these results, it is possible to conclude that the free radical formation occurs in all solar spectral ranges, but especially in the UV range. A significant difference was demonstrated between sunscreens containing AO or not. The sunscreen containing UV filters and AO had a clear protective effect in the UV and VIS regions, and a lower effect in the NIR range. However, considering the very slight radical formation in the NIR range, we believe that more studies are necessary to demonstrate its deleterious effect on the skin, and new strategies must be developed in order to provide good protection in this range as well. Additionally, the skin penetration profile showed that the sunscreen's ingredients were retained in the upper stratum corneum layer, which is very important for the efficacy and safety of such products. So, we hope that the results discussed in the present study can help in the development of effective and safer sunscreen products.

\section{Acknowledgment}

The authors thank the Coordination for the Improvement of Higher Education Personnel (CAPES), Brazil, for providing the sandwich PhD scholarship (grant No. BEX 10271/14-7) to Carla Souza.

\section{Statement of Ethics}

With the approval of the Veterinary Board Dahme-Spreewald, the ears were obtained from a local butcher.

\section{Disclosure Statement}

The authors report no conflicts of interest.

\section{References}

1 Cadet J, Douki T, Ravanat JL: Oxidatively generated damage to cellular DNA by UVB and UVA radiation. Photochem Photobiol 2015;91:140-155.

2 Polefka TG, Meyer TA, Agin PP, Bianchini RJ: Effects of solar radiation on the skin. J Cosmet Dermatol 2012;11:134-143.

3 Grether-Beck S, Marini A, Jaenicke T, Krutmann J: Photoprotection of human skin beyond ultraviolet radiation. Photodermatol Photoimmunol Photomed 2014;30:167-174.
4 Akhalaya MY, Maksimov GV, Rubin AB, Lademann J, Darvin ME: Molecular action mechanisms of solar infrared radiation and heat on human skin. Ageing Res Rev 2014;16: $1-11$.

5 Piazena H, Kelleher DK: Effects of infrared-A irradiation on skin: discrepancies in published data highlight the need for an exact consideration of physical and photobiological laws and appropriate experimental settings. Photochem Photobiol 2010;86:687-705.
6 Zittermann A, Gummert JF: Sun, vitamin D, and cardiovascular disease. J Photochem Photobiol B 2010;101:124-129.

7 Agbai ON, Buster K, Sanchez M, Hernandez C, Kundu RV, Chiu M, Roberts WE, Draelos ZD, Bhushan R, Taylor SC, Lim HW: Skin cancer and photoprotection in people of color: a review and recommendations for physicians and the public. J Am Acad Dermatol 2014;70:748-762. 
8 Dupont E, Gomez J, Bilodeau D: Beyond UV radiation: a skin under challenge. Int J Cosmet Sci 2013;35:224-232.

9 Schroeder P, Lademann J, Darvin ME, Stege H, Marks C, Bruhnke S, Krutmann J: Infrared radiation-induced matrix metalloproteinase in human skin: implications for protection. J Invest Dermatol 2008;128:2491-2497.

10 Randhawa M, Seo I, Liebel F, Southall MD, Kollias N, Ruvolo E: Visible light induces melanogenesis in human skin through a photoadaptive response. PLoS One 2015;10: 0130949.

11 Liebel F, Kaur S, Ruvolo E, Kollias N, Southall MD: Irradiation of skin with visible light induces reactive oxygen species and matrix-degrading enzymes. J Invest Dermatol 2012;132: 1901-1907.

12 Mahmoud BH, Hexsel CL, Hamzavi IH, Lim HW: Effects of visible light on the skin. Photochem Photobiol 2008;84:450-462

13 Zastrow L, Groth N, Klein F, Kockott D, Lademann J, Renneberg R, Ferrero L: The missing link - light-induced (280-1,600 nm) free radical formation in human skin. Skin Pharmacol Physiol 2009;22:31-44.

14 Haywood R, Wardman P, Sanders R, Linge C: Sunscreens inadequately protect against ultraviolet-A-induced free radicals in skin: implications for skin aging and melanoma? J Invest Dermatol 2003;121:862-868.

15 Haque T, Crowther JM, Lane ME, Moore DJ: Chemical ultraviolet absorbers topically applied in a skin barrier mimetic formulation remain in the outer stratum corneum of porcine skin. Int J Pharm 2016;510:250-254.

16 Freitas JV, Praca FS, Bentley MV, Gaspar LR: Trans-resveratrol and beta-carotene from sunscreens penetrate viable skin layers and reduce cutaneous penetration of UV-filters. Int J Pharm 2015;484:131-137.

17 Delsin SD, Fossa MM, Mercúrio DG, Maia Campos PMBG: Clinical efficacy of dermocosmetic formulations containing Spirulina extract on young and mature skin: Effects on the skin hydrolipidic barrier and structural properties. Clin Pharmacol Biopharm 2015;4:4.

18 Neto DC, Camargo FB, Maia Campos PMBG: Cosmetic composition containing spirulina, and cosmetic treatment method. US Patent No US20140023676 A1, 2014. http://xrint. com/patents/us.

19 Li HB, Cheng KW, Wong CC, Fan KW, Chen F, Jiang Y: Evaluation of antioxidant capacity and total phenolic content of different fractions of selected microalgae. Food Chem 2007;102:771-776.

20 Souza C, Freitas APF, Maia Campos PMBG: Topical formulation containing beeswaxbased nanoparticles improved in vivo skin barrier function. AAPS PharmSciTech DOI: 10.1208/s12249-017-0737-x.

21 Hawkins CL, Davies MJ: Detection and characterisation of radicals in biological materials using EPR methodology. Biochim Biophys Acta 2014;1840:708-721.
22 Meinke MC, Syring F, Schanzer S, Haag SF, Graf R, Loch M, Gersonde I, Groth N, Pflucker F, Lademann J: Radical protection by differently composed creams in the UV/VIS and IR spectral ranges. Photochem Photobiol 2013;89:1079-1084.

23 Meinke MC, Haag SF, Schanzer S, Groth N, Gersonde I, Lademann J: Radical protection by sunscreens in the infrared spectral range. Photochem Photobiol 2011;87:452-456.

24 Jacobi U, Kaiser M, Toll R, Mangelsdorf S, Audring H, Otberg N, Sterry W, Lademann J: Porcine ear skin: an in vitro model for human skin. Skin Res Technol 2007;13:19-24.

25 Choe C, Lademann J, Darvin ME: Analysis of human and porcine skin in vivo/ex vivo for penetration of selected oils by confocal Raman microscopy. Skin Pharmacol Physiol 2015;28:318-330

26 Herrling T, Fuchs J, Rehberg J, Groth N: UVinduced free radicals in the skin detected by ESR spectroscopy and imaging using nitroxides. Free Radic Biol Med 2003;35:59-67.

27 Darvin ME, Richter H, Zhu YJ, Meinke MC, Knorr F, Gonchukov SA, Koenig K, Lademann J: Comparison of in vivo and ex vivo laser scanning microscopy and multiphoton tomography application for human and porcine skin imaging. Kvant Electron 2014;44: 646-651.

28 Benech-Kieffer F, Wegrich P, Schwarzenbach R, Klecak G, Weber T, Leclaire J, Schaefer H: Percutaneous absorption of sunscreens in vitro: Interspecies comparison, skin models and reproducibility aspects. Skin Pharmacol Appl Skin Physiol 2000;13:324-335.

29 Ascencio SM, Choe C, Meinke MC, Muller RH, Maksimov GV, Wigger-Alberti W, Lademann J, Darvin ME: Confocal Raman microscopy and multivariate statistical analysis for determination of different penetration abilities of caffeine and propylene glycol applied simultaneously in a mixture on porcine skin ex vivo. Eur J Pharm Biopharm 2016;104:5158.

30 Zhu YJ, Choe CS, Ahlberg S, Meinke MC, Alexiev U, Lademann J, Darvin ME: Penetration of silver nanoparticles into porcine skin ex vivo using fluorescence lifetime imaging microscopy, Raman microscopy, and surfaceenhanced Raman scattering microscopy. J Biomed Opt 2015;20:051006.

31 Fuchs J: Potentials and limitations of the natural antioxidants RRR-alpha-tocopherol, Lascorbic acid and beta-carotene in cutaneous photoprotection. Free Radical Biol Med 1998; 25:848-873.

32 Chen L, Hu JY, Wang SQ: The role of antioxidants in photoprotection: a critical review. J Am Acad Dermatol 2012;67:1013-1024.
33 Sargent EV, Travers JB: Examining the differences in current regulatory processes for sunscreens and proposed safety assessment paradigm. Regul Toxicol Pharmacol 2016;79:125141 .

34 Phongamwong $\mathrm{T}$, Chareonpanich M, Limtrakul J: Role of chlorophyll in spirulina on photocatalytic activity of $\mathrm{CO}_{2}$ reduction under visible light over modified $\mathrm{N}$-doped $\mathrm{TiO}_{2}$ photocatalysts. Appl Catalysis B Environ 2015;168:114-124.

35 Cho S, Shin MH, Kim YK, Seo J-E, Lee YM, Park C-H, Chung JH: Effects of infrared radiation and heat on human skin aging in vivo. J Invest Dermatol Symp Proc 2009;14:15-19.

36 Schieke SM, Stege H, Kurten V, Grether-Beck $\mathrm{S}$, Sies H, Krutmann J: Infrared-A radiationinduced matrix metalloproteinase 1 expression is mediated through extracellular signalregulated kinase $1 / 2$ activation in human dermal fibroblasts. J Invest Dermatol 2002;119: 1323-1329.

37 Lohan SB, Muller R, Albrecht S, Mink K, Tscherch K, Ismaeel F, Lademann J, Rohn S, Meinke MC: Free radicals induced by sunlight in different spectral regions - in vivo versus ex vivo study. Exp Dermatol 2016;25:380385

38 Ashtikar M, Matthaus C, Schmitt M, Krafft C, Fahr A, Popp J: Non-invasive depth profile imaging of the stratum corneum using confocal Raman microscopy: first insights into the method. Eur J Pharm Sci 2013;50:601-608.

39 Caspers PJ, Lucassen GW, Carter EA, Bruining HA, Puppels GJ: In vivo confocal Raman microspectroscopy of the skin: noninvasive determination of molecular concentration profiles. J Invest Dermatol 2001;116:434-442.

40 Choe C, Lademann J, Darvin ME: A depthdependent profile of the lipid conformation and lateral packing order of the stratum corneum in vivo measured using Raman microscopy. Analyst 2016;141:1981-1987.

41 Nash JF, Tanner PR: Relevance of UV filter/ sunscreen product photostability to human safety. Photodermatol Photoimmunol Photomed 2014;30:88-95.

42 Durand L, Habran N, Henschel V, Amighi K In vitro evaluation of the cutaneous penetration of sprayable sunscreen emulsions with high concentrations of UV filters. Int J Cosmet Sci 2009;31:279-292.

43 Adlhart C, Baschong W: Surface distribution and depths profiling of particulate organic UV absorbers by Raman imaging and tape stripping. Int J Cosmet Sci 2011;33:527-534.

44 Heng KY, Kei TY, Singh KJ, Hairui LI, AiLing POH, Lifeng K: Handbook of Cosmeceutical Excipients and their Safeties. Elsevier Store, Cambridge, UK, 1st Edition, p.163. ISBN 978-1-908818-71-3, 2014

45 Sobanska AW, Pyzowski J: Quantification of Sunscreen Ethylhexyl Triazone in Topical Skin-Care Products by Normal-Phase TLC/ Densitometry. Scientific World Journal. 2012; 2012: 807516. 